\title{
Diagnostic Sensitivity
}

National Cancer Institute

\section{Source}

National Cancer Institute. Diagnostic Sensitivity. NCI Thesaurus. Code C41394.

The probability that a test will produce a true postive result when used on effected subjects as compared to a reference or "gold standard". The sensitivity of a test can be determined by calculating: number of true positive results divided by the sum of true positive results plus number of false negative results. 